\title{
Learners’ Cognitive Styles and Foreign Language Teaching*
}

\author{
ZHANG Yan-qiu, BIAN Wei \\ Changchun University, Changchun, China
}

\begin{abstract}
Individual learners possess distinctive cognitive styles which have a great effect on foreign language learning. The present paper intends to study the relationship between foreign language learning proficiency and cognitive styles from the perspectives of psychology, psycholinguistics, and second language acquisition. Through the analysis, the author has arrived at a conclusion that learners with different cognitive styles adopt quite different strategies in learning a foreign language. The best-matched methods fitting for different cognitive styles may help learners improve their learning proficiency. Therefore, in order to improve teaching proficiency, foreign language teachers should keep a match between learners’ cognitive styles and teaching methodologies.
\end{abstract}

Keywords: cognitive styles, field independence, field dependence, reflectivity, impulsivity, convergent, divergent

\section{Introduction}

As a psychological term, cognitive style refers to the manifested individual differences, which include the differences not only in the aspects of cognitive process such as individual perception, memory, and thinking, but also in the aspects of cognitive function and ability in the course of information processing. Cognitive style, therefore, reflects the totality of psychological functioning. An individual's cognitive style is viewed as relatively fixed and not readily changed. It closely relates to cognitive strategies and individual characters because the adopted style in the course of information processing is considered to be the most suitable one by the individual, and the individuals with different characters take different ways of thinking. Cognitive style differs from intelligence, which is the showed differences in the intelligence test or the scholastic test and has only one dimension, but cognitive style has two extremes. However, to some extent, it is similar to intelligence because it is relatively fixed.

Cognitive style has been studied in the fields of general psychology and educational psychology. With the transfer of language teaching focus from teachers to students since the 60 s of last century, the research focus of language educationalists and researchers also transfers from the study of teaching methodologies and process to language learners' learning process and their individual characters. Therefore, language learners' differences such as personality, attitudes, motivation, and cognitive style have increasingly attracted the attention of second language acquisition researchers. The study of learning process and learning mechanism becomes more and more

\footnotetext{
* This paper is the phased research results of the planning projects of 2014 Jilin Science Education Twelfth Five-Year Plan "Study on Multiple Interactive School-Based Education Model of College English Teachers” (Project Number: GH14265); 2014 Jilin Social Science Fund Project “Study on College English Teachers’ Knowledge Structure” (Project Number: 2014B204).

ZHANG Yan-qiu, lecturer, master, Public Foreign Languages Teaching and Research Department, Changchun University. BIAN Wei, lecturer, master, Public Foreign Languages Teaching and Research Department, Changchun University.
} 
important because in any teaching activities, "teaching" is only a means, whereas "learning” is the ultimate purpose, and the ultimate standard of measuring teaching effects is not the results of teaching but the results of learning. However, cognitive style has not been given a very clear definition until now, and different researchers give different classifications of it. For instance, Messick (1984) classifies cognitive style into 19 kinds, whereas Riding and Cheema (1991) classify it into 30 kinds, which reflect the researchers' different research style and emphasis. Language learners, with different cognitive styles, usually have different interest, personality, emotion, motivation, and so on, which to a certain extent determine their attitudes towards different kinds of learning tasks and materials, their behaviors in the classroom activities, and their relations with the teachers. The study of foreign language teaching should attach importance to language learners' cognitive styles.

\section{Relationship Between Cognitive Styles and Language Learning}

As mentioned above, a number of cognitive style distinctions have been made in the field of cognitive psychology. Bruner, Goodnow, and Austin (1957) distinguish "focusers" and "scanners". Focusers take a step-by-step approach to deal with problems and concentrate on one feature at a time. However, scanners deal with all or several features at the same time. Pask and Scott (1972) distinguish between "serialists" and "holists". Serialists refer to the learners who operate with simple hypotheses, whereas holists refer to those who deal with complex hypotheses. There are other distinctions, such as field dependence versus field independence, reflectivity thinking versus impulsivity thinking, convergent thinking versus divergent thinking, holistic strategy versus analytic strategy, introversion versus extroversion, etc. (Ellis, 1994). But until now linguists put much emphasis on the three former kinds. The present paper intends to study the relations between these three kinds of cognitive styles and language learning.

\section{Field Dependence and Field Independence}

The distinction between field dependence and field independence has attracted much attention in second language acquisition research. The so-called "field" refers to the surroundings, which have different influences in degree on people's consciousness. People who are less or hardly influenced by the surroundings are called field independence learners, whereas people who are easily influenced by the surroundings are called field dependence learners. Further studies show that field dependence and field independence broadly exist in the aspects of memory, thinking, personality, and so on. Generally speaking, field independent learners have the following psychological characters: knowing their own mind, independence, staying alone, being interested in abstract theories, and being good at mathematics and natural science. On the contrary, field dependence learners are not very independent. They depend strongly on people around them, pay much attention to others' responses in social intercourse and try their best to make them accord with the social environment. They are more interested in literal arts and social sciences. In terms of age, field independence male learners are more than female learners and field dependence female learners are more than male learners. In addition, the degree of dependence on the surroundings changes with the increase of age. The younger the learners are, the more highly they depend on the surroundings. Then, what is the relationship between field independence/field dependence and L2 learning achievement or communicative abilities?

Linguistic educationalists have made many studies on field independence/field dependence and drawn the similar conclusion that field independence cognitive style is beneficial to L2 learning. Foreign studies show that 
field independence learners have stronger communicative abilities, whereas field dependence learners are more proficient in language, and the differences between them increase with the extension of time. The study investigating the Chinese students made by WU and LIU (1993) shows that field independence learners score higher than field dependence learners in foreign language tests. Thus, they draw a conclusion that in the initial stage of language learning, field independence learners and field dependence learners may not show obvious differences, but when reaching a certain level, field independence learners gradually manifest their advantages. What is the reason for the occurrence of this change? Generally speaking, the learners score better when learning is in accordance with their cognitive styles. However, because field dependence learners are easy to be influenced by surroundings and to accept others' hint, even if their learning is in accordance with their cognitive styles, they may not score high. On the contrary, field independence learners achieve better learning effects because of their internal motivation. Learners have to take great pains to master a foreign language. Therefore, it is easy to understand the advantages of field independence L2 learners in the higher stage of language learning.

\section{Impulsivity and Reflectivity}

Kagan (1966) is the first to propose the distinction between reflectivity and impulsivity. In the course of solving problems, some people make a quick response according to the first impression and the first thing they think of, but others are likely to look before they leap, and then to arrive at a conclusion. The former are called impulsivity thinkers, and the latter are called reflectivity thinkers. In study, impulsivity learners can quickly form their own opinions and respond to the questions, and they are good at analyzing problems as a whole, but they pay less attention to accuracy of the answers. On the contrary, reflectivity learners may spend more time in coming to a conclusion because they put much emphasis on details and accuracy of the answers. Thus, each has its own merits, and the ability to resolve problems has no essential difference.

Foreign studies show that impulsivity learners' reading speed is faster than reflectivity learners, but the latter's answers are more accurate, and they score higher than the former. The results of the study made by Jamieson (1992) show that the testees with rapid speed and accuracy are excellent learners. In fact, the excellent language learners he believes are those who can make use of the advantages of both reflectivity and impulsivity.

\section{Convergent Thinking and Divergent Thinking}

Convergent thinking, which is also called comprehensive thinking, refers to the way of thinking of gathering or synthesizing all the information and knowledge relating to the problems, whereas divergent thinking disperses concept into many relevant fields and usually closely relates to creativity. The differences between these two kinds of cognitive styles are as follows: (1) Interests are different. Convergent thinkers are interested in natural science, but divergent thinkers are interested in liberal arts. (2) The adopted strategies of information processing are different. Convergent thinkers only pay attention to some aspects of things, and they can quickly restrict their thinking to a certain field. On the contrary, divergent thinkers adopt searching strategies and pay attention to many things. (3) In the course of solving problems, convergent thinkers usually find out a definite answer according to the provided information, but divergent thinkers are good at finding out many accepted answers. The studies also find that divergent learners score better in field independence area and they are adept in studying highly creative subjects.

In foreign language study, learners with divergent thinking are able to study L2 more creatively with the 
help of all kinds of knowledge. They are efficient in their study and can better resist the interference of the first language. The traditional language teaching methodologies, which focus on the teachers, stress explicitness of knowledge teaching and seek the only answer to the question, are more suitable for convergent learners. However, communicative language teaching methods, which stress the role of learners and request them to give full scope to their creativity, are more suitable for divergent learners.

\section{Implications on Foreign Language Teaching}

The study of cognitive styles has many effects on foreign language teaching, and the following three points are worth mentioning.

First, the study of cognitive styles can help foreign language teachers know the students very well and adopt appropriate teaching methodologies and materials. There is no absolutely ineffective teaching method in the world. The teaching method is only ineffective on condition that it does not fit the students' characters. As a teacher, the task of first importance for him/her is to know students' cognitive characters and personality well, to adopt appropriate teaching methodologies and materials, and to put the teaching process into practice. Of course, it is impossible and unrealistic to satisfy all the students' tastes and demands. But if teachers can have a basic understanding of the students and give proper and timely guidance, the students' enthusiasm will be brought into full play. As mentioned above, field dependence learners may have some advantages in the initial stage of foreign language learning because they have stronger ability in social communication. However, as the learning becomes more and more difficult, these learners will not be as good as field independence learners. In this case, if teachers can give appropriate guidance, the learning proficiency will be greatly improved. In addition, in actual teaching activities teachers can impel students to change styles through all kinds of means (such as teaching materials and learning tasks) so that the students can make up for their deficiency in cognitive styles. For instance, teachers can encourage field independence learners to talk with classmates, teachers, and foreigners, to take active part in the activities such as English corner and English speech contest. Even in the class teachers should give them opportunities to show themselves. On the contrary, teachers should assign field dependence learners some homework that needs to be finished by themselves, give enough encouragement when their learning is at a low tide and encourage them to bravely express their opinions.

Second, teachers should deal well with the relation between language fluency and accuracy in foreign language teaching. At present, the conspicuous problem existing in foreign language teaching in China is that students' communicative ability in spoken language is too poor, which certainly relates to the adopted traditional teaching methodologies that emphasize accuracy, but these methodologies cannot be abandoned. Impulsivity learners speak actively and fluently in class, but they often make mistakes, so the traditional teaching methodologies suit them, and teachers should pay more attention to their mistakes and try their best to correct them. On the contrary, reflectivity learners are reticent in class, and their opinions are more accurate after careful consideration, but they cannot express them very fluently. Thus, as for them, communicative language teaching methodologies are more suitable. Teachers should be more tolerant of their mistakes in class and make fewer corrections if the mistakes do not affect the meaning of their expressions. In addition, being good at logical thinking, reflectivity learners are superior in the learning tasks that need inference, so teachers should assign them more learning materials and tasks of this kind. However, it does not mean not assigning this kind of learning 
materials and tasks to impulsivity learners. It is necessary to make each of both have its own emphasis.

Finally, learners with different cognitive styles show different features in their L2 development. Impulsivity learners may make rapid but less progress, and their steady period is short, whereas reflectivity learners may make slow but obvious progress, and their steady period is long. Therefore, teachers should have a full understanding of this, adopt appropriate language teaching methodologies, and give practical guidance.

\section{Suggestions on the Study of Learners' Cognitive Styles}

Most researchers have put much emphasis on the issue that which cognitive style or character is more suitable for L2 learning, but the author believes that this kind of study is in vain because it is impossible to say which cognitive style works best. Going to the extremes is harmful to learning. Quite possibly it is learners who display flexibility who are most successful. The study of learners' cognitive styles aims to help teachers understand learners well and find out teaching methodologies, learning materials, and learning tasks that are fit for learners' characters. Only in this way, can teachers teach students according to their abilities. The author suggests that schools at different levels should give students appropriate psychological measures and that these measures should use many kinds of tools and methods. In this case, teachers may have a full understanding of students' cognitive styles and personality. Because any kind of measuring tool reflects the designer's inherent theoretical model and concept and has its own limitations, in order to measure the students' characters many kinds of measuring tools should be used.

\section{Conclusion}

To sum up, the achievements of the study of learners' cognitive styles should be applied to practice. Therefore, in order to improve language teaching proficiency, foreign language teachers should keep a match between learners' cognitive styles and teaching methodologies.

\section{References}

Bruner, J., Goodnow, J., \& Austin, G. (1957). A study of thinking. New York: Wiley and Sons.

Ellis, R. (1994). The study of second language acquisition. Oxford: Oxford University Press.

Jamieson, J. (1992). The cognitive styles of reflection/impulsivity and field independence/dependence and ESL success. The Modern Language Journal, 76(4), 491-501.

Kagan, J. (1966). Reflection-impulsivity: The generality and dynamics of conceptual tempo. Journal of Abnormal Psychology, 71, 17-24.

Messick, S. (1984). The nature of cognitive styles: Problems and promise in educational practice. Educational Psychologist, 19(2), 59-74.

Pask, G., \& Scott, B. C. E. (1972). Learning strategies and individual competence. International Journal of Man-Machine Studies, 4, 217-253.

Riding, R. J., \& Cheema, I. (1991). Cognitive styles: An overview and integration. Educational Psychology, 11, 193-215.

WU, Y. A., \& LIU, R. Q. (1993). A survey on the quality of Chinese undergraduates major in English. Foreign Language Teaching and Research, 1, 36-46. 